\title{
A DFuzzy Evaluation Model for the Development of Cultural and Creative Industries-Example of Industries with Local Characteristics in Taiwan
}

\author{
Chia-Hui Huang ${ }^{1}$, Danji Qu ${ }^{2}$, Shu-Yin $\mathrm{Hsueh}^{3, *}$ \\ Graduate Institute of Cultural and Creative Design \\ TungFang Design Institute \\ 110, Tung Fang Road, Hu-Nei District Kaohsiung City, 82941, Taiwan \\ ${ }^{1}$ E-mail: judy_huang@mail.tf.edu.tw \\ ${ }^{2}$ E-mail:g3665227047@gmail.com \\ ${ }^{3}$ E-mail: master.s.03269@gmail.com; Telephone: +86-933373708 \\ * Corresponding author.
}

\begin{abstract}
In recent years, Taiwan has been proactively promoting the development of its cultural and creative industries and the development of local cultural characteristics. In addition, it has been encouraging the integration of industrial development and cultural elements to create unique industrial competitiveness. The development of cultural values has become a major policy objective. To explore the influence factors regarding the development of cultural and creative industries, the Delphi method is used in this study to establish the evaluation criteria based on the collective opinions of invited experts. Then the fuzzy logic theory is used to establish a quantification model for the development of cultural and creative industries with local characteristics. This model can be used by not only the industries to evaluate the effectiveness of incorporating local cultural characteristics in their development but also the regulators to find out references for their decision making of the subsidy standards for the development of industries with local characteristics.
\end{abstract}

Keywords-cultural and creative industries; cultural values; Delphi method; fuzzy logic theory; industries with local characteristics

\section{INTRODUCTION}

Recently, Taiwan has seen a further slowdown in its economic development and also increasing competition from the technology industries in China and Korea. Under such circumstances, the cultural and creative industries have gradually become a major strategic pillar for Taiwan's economic development. The cultural and creative industries are seen as "the fourth wave" of economic growth momentum. To establish an enabling environment for such industries and fulfill their intangible values and cultural economics [1], Taiwan invested totally NT $\$ 9.849$ billion in these industries from 2002 to 2009. Moreover, on May 14 ${ }^{\text {th }}$, 2009, the Executive Yuan of Taiwan's government also launched the "Creative Taiwan-2009-2013 Development Program of the Cultural and Creative Industries" [2].

The development of cultural and creative industries has spanned across many sectors in Taiwan and become the next strategic driving force after the electronic industry for Taiwan's future economic development. During recent years, more attention has been invested in the development of cultural and creative industries with "local characteristics" with a view to not only promoting local development but also reducing the government's difficulties and budgets in promoting development in rural/remote areas. This is in line with the findings of Wojan's 2007 research, "Creative Capital's Contribution to Local Manufacturing Competitiveness" [3]. The current "One Town One Product" (OTOP) policy in Taiwan is expected to promote the development of diversified industries [4], such as traditional craft, product processing, agriculture, culinary culture, cultural products and tourism.

Currently, the countries relatively successful in promoting their cultural and creative industries are the UK, the US, South Korea, China, Japan, Finland, France, Germany, Italy, Australia, New Zealand, Denmark, Sweden, the Netherlands, Belgium, Switzerland, Thailand and India. In terms of government's role and policy continuity/comprehensiveness, the UK is worldly recognized as the first country to propose its national policy of "creative industries" [5], which has yielded a significant influence on its overall economic development. Many other countries have included the creative industries as part of their major development policies. In addition, other issues such as cultural industries [6], cultural products, cultural values, cultural capital [7], cultural economics [8], and copyright $[9,10]$ all have a significant influence on a country's overall economic development. Cultural product industries and urban economic development are beneficial for a country's global competitiveness [11].

The US is the only country in the world that directly refers to the cultural and creative industries as "copyright industries," which can be divided into "core copyright industries", "interdependent industries" and "non-dedicated support industries". With their innovative technologies and inventions protected by intellectual property (IP) rights and patents, the copyright industries in America has been making significant contributions to the US economy. According to 
"the Copyright Industries in the U.S. Economy-The 2012 Report" [12], the 2012 output of the copyright industries in the US totaled US\$1.7652 trillion with US\$1.0156 trillion from the core copyright industries, US\$351.4 billion from the interdependent industries, and US\$398.1 billion from the nondedicated support industries. In addition, as indicated in Table 1 that lists the annual contributions of the copyright industries to the US GDP from 2009-2012, the industries contributed over $11 \%$ to the GDP each year during these four years, demonstrating the importance of these industries to the overall development of America. Though not the first to develop cultural and creative industries, the US is the largest economy in the world and the development of its industries has a direct or indirect influence on the economic development strategies of many other countries. Moreover, different from Taiwan's attention to the development of cultural and creative industries with "local characteristics", the US is focusing more on the development of non-dedicated support industries.

TABLE I. ANNUAL OUTPUT AND GDP CONTRIBUTION OF THE US COPYRIGHT INDUSTRIES FROM 2009 TO 2012 (IN US\$1 BILLION)

\begin{tabular}{|l|l|l|l|l|}
\hline Year & $\mathbf{2 0 0 9}$ & $\mathbf{2 0 1 0}$ & $\mathbf{2 0 1 1}$ & $\mathbf{2 0 1 2}$ \\
\hline $\begin{array}{l}\text { Core } \\
\text { Copyright } \\
\text { Industries }\end{array}$ & $\$ 884.8$ & $\$ 910.4$ & $\$ 965.1$ & $\$ 1,015.6$ \\
\hline US GDP & $\$ 13,973.7$ & $\$ 14,498.9$ & $\$ 15,075.7$ & $\$ 15,684.8$ \\
\hline $\begin{array}{l}\text { Contribution } \\
\text { to GDP }(\%)\end{array}$ & $6.33 \%$ & $6.28 \%$ & $6.40 \%$ & $6.48 \%$ \\
\hline Year & 2009 & 2010 & 2011 & 2012 \\
\hline $\begin{array}{l}\text { Copyright } \\
\text { industries }\end{array}$ & $\$ 1,541.6$ & $\$ 1,596.2$ & $\$ 1,681.9$ & $\$ 1,765.2$ \\
\hline US GDP & $\$ 13,973.7$ & $\$ 14,498.9$ & $\$ 15,075.7$ & $\$ 15,684.8$ \\
\hline $\begin{array}{l}\text { Contribution } \\
\text { to GDP }(\%)\end{array}$ & $11.03 \%$ & $11.01 \%$ & $11.16 \%$ & $11.25 \%$ \\
\hline
\end{tabular}

\section{LITERATURE REVIEW}

According to David Hesmondhalgh, the core industries of the cultural and creative industries cover music (music industry), narrative (advertisement and marketing) and performance (movies, TV and broadcasting) while the peripheral industries include theaters, visual art production and marketing, sports, software, consumer electronics, fashion, tourism, handcraft and architecture [13]. According to this definition, the cultural and creative industries cover a very wide range and involve many supply chains. With art and culture as part of major national development strategies and Culture as Commodity [14], the cultural and creative industries have gradually become indispensable considerations for economic development policies. In a study in 2011, Lyudmila Petrova explored the influences and contributions of cultural diversity, sustainable economy, and ecology/culture [15]. An extension of her research by incorporating "development based on local characteristics" in the discussion will probably lead to more interesting findings.

The new economic concept of using art and culture to promote economic growth has been established and proven. For example, according to the research by Sintas et al. in 2002 [16], the "new consumer theory" has various implications for both cultural policymaking and marketing of cultural products. Incorporation of cultural elements in industrial development is indeed helpful for international marketing of products. A case in point is Creative Britain, through which people around the world have become more aware of not only the UK's industrial innovativeness, creativity and public puolicy but also the achievements of the UK's investments in promoting the development of creative industries [17]. However, as indicated by Collins, there is still bureaucracy in parts of the UK's creative industries policy, which imposes unfavorable conditions or regulations on new designers or new industries. These are attention-worthy issues for countries that have been eagerly promoting their cultural and creative industries. The growing attention to cultural and creative industires, particularly in developing countries, is mainly a result of increasing product competition due to globalization. Placing emphasis on the cultural uniqueness and values of products is all intended to enhance the products' internal and external competivneness. In Taiwan, the development policy of cultural and creative industires focuses on industries with "lcoal characteristics" with a view to boosting local industries and econmic development. It is like what Trimarchi described in his 2002 research as "the combination of territorial and diachronic features of creativity as the condition for a new rise to occur, due to the effective use of policy tools" [1].

The industries with local characteristics can mainly be divided into categories such as natural landscape tourism, agricultural product/processing, craft, cultural/artistic products, and festive activities [4]. Despite their less developed traffic and other public infrastructures, the remote and/or rural areas in Taiwan still enjoy several production cost advantages such as low labor costs. According to Wojan, SMEs of the cultural and creative industries returning to rural areas can enjoy several advantages and make contributions to local manufacturing competitiveness [3]. In addition to enjoying advantages such as supportive governmental policies and lower costs, SMEs developing based on local characteristics in rural/remote areas of Taiwan can also help to create jobs locally, boost local economic development, narrow down the gaps between rural and urban areas, facilitate local industrial transitions, stimulate local development of tourism, and promote development and marketing of local cultural products. According to Tyler Cowen [18], cultural economics can change people's lives. Daniel Mato pointed out the connections between consumption and culture in his "All industries are cultural" paper in 2009 [19]. The values of cultural economics are exactly beyond price as aptly suggested by the title of the book, Beyond Price. Value in Culture, Economics and the Arts [20]. From the above-mentioned discussions, the benefits of governmental policies to promote cultural and creative industries with local characteristics are illustrated.

By integrating knowledge capital of industries and social/cultural elements of an area or a country, cultural and creative industries can create unique professional services and products, which consequently helps to boost their knowledge capital and increase the competitiveness of their products. The integration of cultural and creative industries with local characteristics are helpful for local SMEs in their redevelopment and transition. The other key factors for industrial success include brand $[21,22]$, renovation of cultural 
tradition [23], fashion/taste and appealing colors [24], product differentiation [25], hedonic and functional designs [26,27]. In addition, knowledge generation and transfer are essential for a firm's sustainable competitive advantages [28]. In this study, the Delphi method and fuzzy logic are used to establish a policy-making assistance model for policy-makers and regulators to evaluate the development results of cultural and creative industries with local characteristics.

\section{RESEARCH DESIGN AND METHODS}

\section{A. Delphi Method}

The Delphi method is a method to obtain the latest professional knowledge through interactions and communications among experts. Its application is not limited to forecasting the future development of a policy and its implementation [29]. The method is also called "expert investigation method," in which opinions from experts are collected through questionnaires and then compiled several times before the experts reach consensus. In the Delphi method, all the experts express their opinions anonymously and there is no direct communication among them in order to avoid any interference with the representativeness and reliability of their opinions. The Delphi method has been used in a wide variety of research, such as qualitative research [30], research on environmental protection [31], and research on redeveloping derelict public buildings [32].

\section{B. Fuzzy Logic Theory}

Fuzzy logic is the most suitable tool to quantify semantic ambiguity. It has been widely applied in different fields such as fuzzy household appliances, robots, automatic control, and medicine. In addition, fuzzy logic can tolerate uncertain, imprecise, and semantically ambiguous information. Therefore, it is ideal for processing complicated information/data difficult to quantify. There are two types of fuzzy logic inference systems: mamdani and sugeno. Generally, the outputs of mamdani-type systems are continuous while those of sugeno-type systems are discrete. Fuzzy logic has been used in research on issues such as group decision making in fuzzy environments [33], environmental protection education [34], and evaluation of households' energy conservation performance [35].

\section{Delphi Fuzzy Model Framework}

The Delphi fuzzy model framework in this research is composed of three sections. In the first section, experts are consulted to provide opinions, information and data suitable for this research. In the second section, relevant parameters required for the fuzzy logic modeling are confirmed through the Delphi process, such as input criteria, fuzzy set, fuzzy set range, membership function, IF-THEN rules and output criteria. The third section is the quantification by the fuzzy logic inference system (FLIS). The FLIS quantification process is: input scenario, fuzzifier, inference engine, defuzzified, and finally output value (quantity). The Delphi fuzzy model framework is illustrated in Fig. 1 as follows:

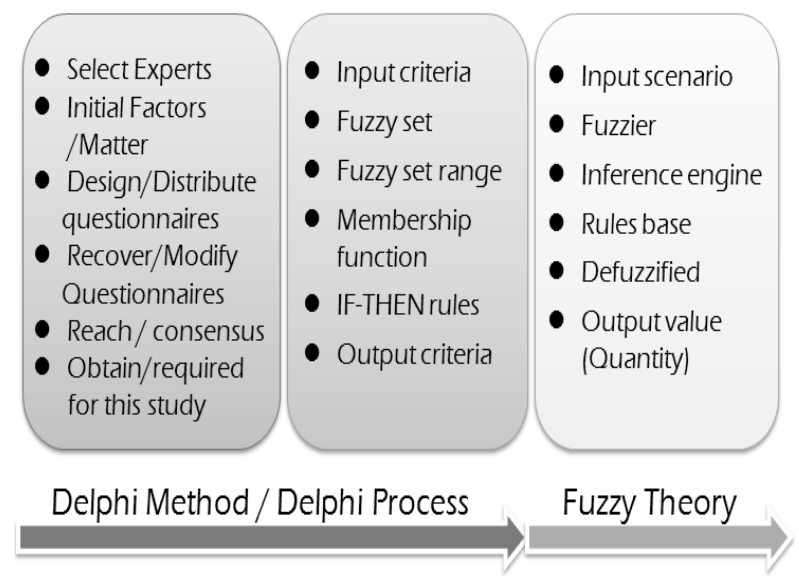

Fig. 1. The framework of the evaluation model

\section{Influence Factors and Parameters}

There are totally eight Delphi experts in this research. Among them, three are industrial managers, two scholars and three working in governmental organizations. Each of them has over 10 years of working in fields relevant to this research. After six and a half months of Delphi process, four influence factors for the development of cultural and creative industries with local characteristics are confirmed: brand, product differentiation, functional design, and knowledge generation. Also through the Delphi process, the following parameters for the influence factors are confirmed: fuzzy set, fuzzy range and membership function as well as the fuzzy set, fuzzy range and membership function of the outputs (see Table 2).

TABLE II. PARAMETERS OF THE INFLUENCE FACTORS IN THIS STUDY

\begin{tabular}{|c|c|c|}
\hline $\begin{array}{l}\text { Influence } \\
\text { Factor }\end{array}$ & Range (Fuzzy set) & Output value \\
\hline Brand & $\begin{array}{l}1-100 \% \\
\text { (Good, Common, Poor) }\end{array}$ & \multirow{4}{*}{$\begin{array}{l}\text { Very good }(>90) \\
\text { indicating international } \\
\text { competitiveness } \\
\text { Good }(80-89) \text { indicating } \\
\text { regional competitiveness } \\
\text { Common }(70-79) \\
\text { Poor }(60-69) \\
\text { Very Poor }(<59)\end{array}$} \\
\hline $\begin{array}{l}\text { Product } \\
\text { differentiation }\end{array}$ & $\begin{array}{l}1-10 \% \\
\text { (High, Common, Low) }\end{array}$ & \\
\hline $\begin{array}{l}\text { Functional } \\
\text { design }\end{array}$ & $\begin{array}{l}1-100 \% \\
\text { (Good, Common, Poor) }\end{array}$ & \\
\hline $\begin{array}{l}\text { Knowledge } \\
\text { generation }\end{array}$ & $\begin{array}{l}1-100 \% \\
\text { (Good, Common, Poor) }\end{array}$ & \\
\hline
\end{tabular}

As for the membership function of each influence factor in this research, the triangle membership function is used. The membership functions of brand and product differentiation are shown respectively in Figs. 2 and 3. The two influence factors have different quantification range and their fuzzy sets are different in quantified semantic contents. The quantification range of brand is from 0 to 100 while its fuzzy set combination is good, common and poor. The quantification range of product differentiation is from 0 to 10 while its fuzzy set combination is good, common and poor. The FLIS quantification is capable of processing different factors of different quantification units or ranges. 


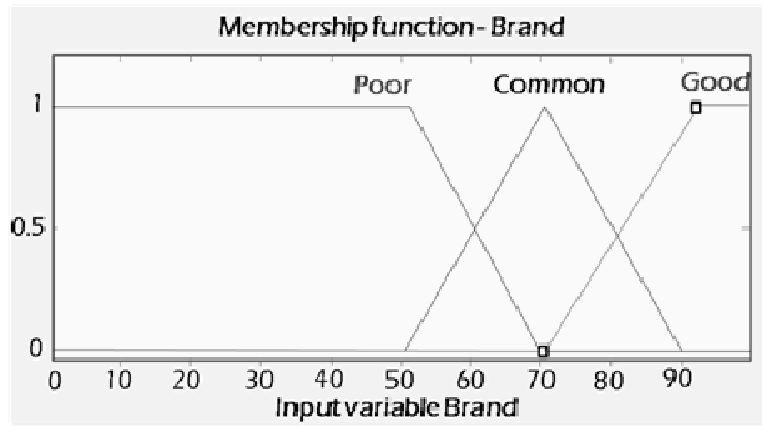

Fig. 2. Membership function of brand

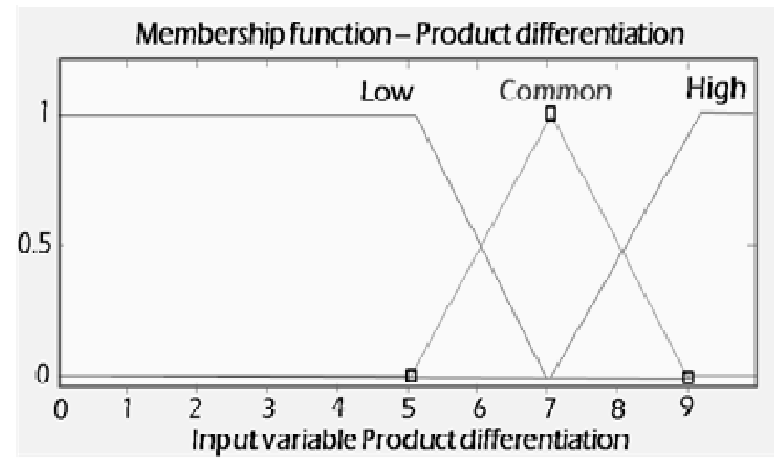

Fig. 3. Membership function of product differentiation

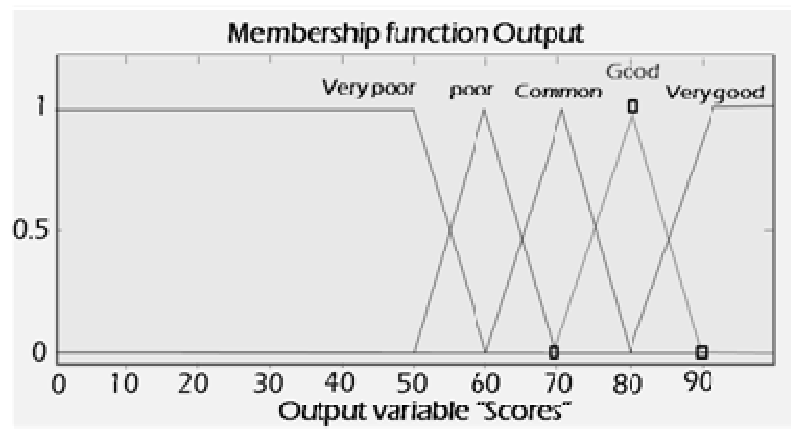

Fig. 4. Membership function of output

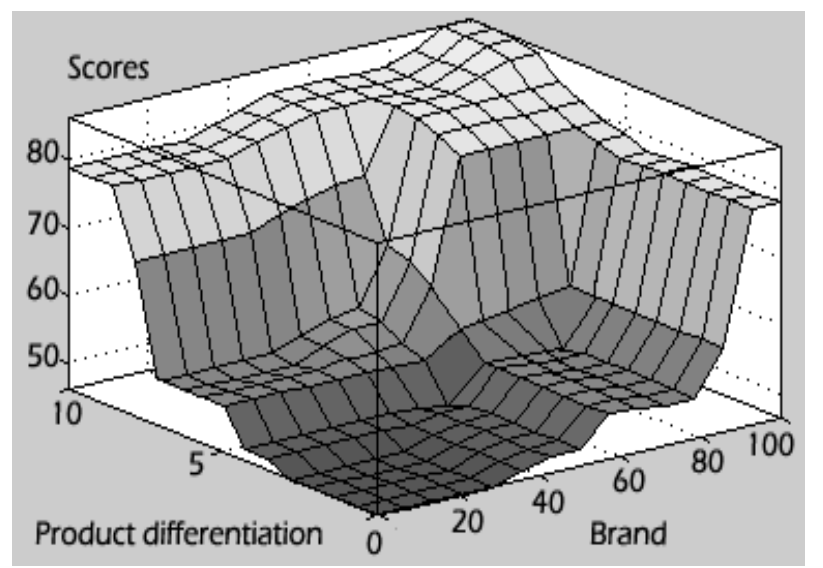

Fig. 5. 3D illustration of the connections between "brand" and "product differentiation"

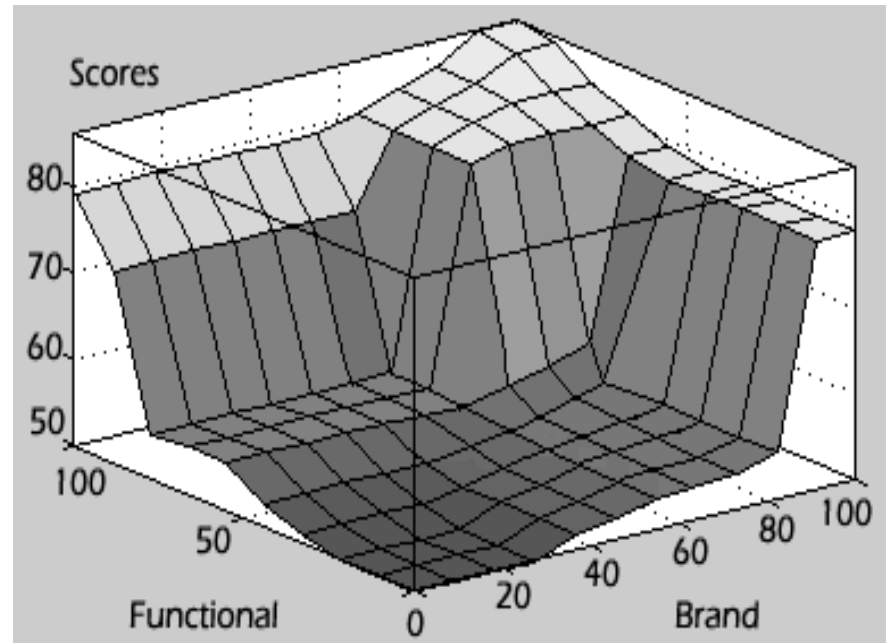

Fig. 6. 3D illustration of the connections between "brand" and "functional design"

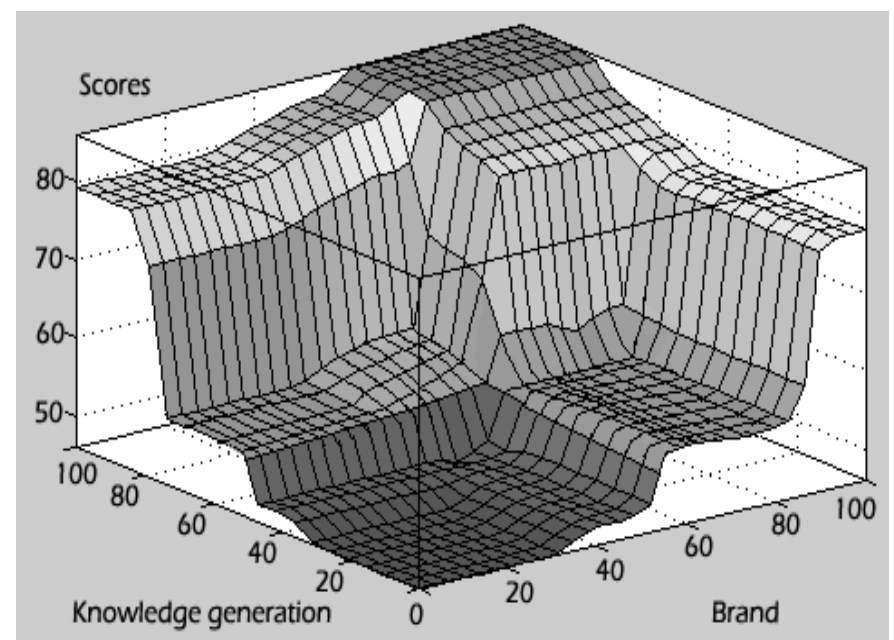

Fig. 7. 3D illustrations of the connections between "brand" and "knowledge generation"

Each of the influence factors in Table 2 has different units or ranges. However, with the fuzzifier, IF-THEN rules and defuzzifier of the FLIS, the input conditions of the factors can be converted into quantified outputs. In fuzzy logic, the input semantics are defined and quantified based on the membership functions. There are four influence factors in this study and each factor has three input conditions. For example, the influence factor of brand has three input conditions: good, common and poor. Therefore, with four influence factors, there are totally $81(3 * 3 * 3 * 3)$ input condition combinations. Each input condition is converted by the FLIS into a quantified output value. Fig. 5 is the 3D illustration of the inputs and outputs of the "brand" and "product differentiation" factors. Fig. 6 is the 3D illustration of the inputs and outputs of "brand" and "functional design" factors. Fig. 7 is the 3D illustration of the inputs and outputs of "brand" and "knowledge generation" factors. 


\section{DELPHI FuZZY MOdEL APPLICATION AND CASE ANALYSIS}

\section{A. Delphi Fuzzy Model Application}

As indicated in Figs. 5, 6 and 7, there are 81 combinations of inputs from the four influence factors. In addition, the influence factors are different in their semantic contents for evaluation. Therefore, the FLIS definition process has to process the influence factors different in their quantification units or ranges. The model developed in this study is capable of converting the 81 complicated input combinations into information that is easy to analyze. It is a complicated computation procedure that ordinary mathematic formula cannot handle.

After the evaluation of the cultural and creative industries with local characteristics in Taiwan using The Dephi fuzzy model developed in this study, the best output value is 96.1 points and the worst output value is 33 points (see Table 3 for all the evaluation results). In addition, the model in this study is also used to evaluate the existing local industriesand the output value is 52.7 points.

\section{B. Case Analysis}

The gradual economic transition in Taiwan from the 1970s to 1980 s had not only widened the rural-urban disparities but also worsened the environment for development of traditional industries in the rural and remote areas. Moreover, the exodus of Taiwan's manufacturing and electronic industries to China, Vietnam, Indonesia, the Philippines, Thailand and other countries has greatly dampened the industrial development and employment in Taiwan. Recently, Taiwan has been proactively developing its cultural and creative industries by providing several supportive policies and subsidies. In particular, there are subsidies for the development of industries with local characteristics with a view to promoting redevelopment and transition of local industries in rural/remote areas.

In this research, two cases of traditional industries were analyzed through the Delphi process and their evaluation results are shown in Table 4 . From the evaluation results, it can be found that the traditional industry in Case 1 have "high" product differentiation and "good" functional design. However, since most companies are family-owned companies in this industry, they generally do not invest in R\&D activities. Therefore, the evaluation result of knowledge generation in Case 1 is "common". Moreover, the traditional industry in Case 1 have brands recognized in more than one area in Taiwan while the traditional industry in Case 2 have no brand of such kind. None of the industries in Case 1 or Case 2 has internationally known brands. Therefore, the evaluation result of the brand in Case 1 is "common" while that in Case 2 is "poor". After the FLIS quantification, the score of Case 1 is 84.8 points, indicating "good" development of the industry in Case 1 while the score of Case 2 is 76.9 point, indicating "common" development of the industry in Case 2.
TABLE III. PARAMETERS OF THE INFLUENCE FACTORS IN THIS STUDY

\begin{tabular}{|l|l|l|}
\hline Influence Factor & Best & Worst \\
\hline Brand & Good & Poor \\
\hline Product differentiation & High & Low \\
\hline Functional design & Good & Poor \\
\hline Knowledge generation & Good & Poor \\
\hline Output value & 96.1 & 33 \\
\hline
\end{tabular}

TABLE IV. ANALYSIS RESUlts OF CASE1 AND CASE 2

\begin{tabular}{|l|l|l|}
\hline Influence Factor & Case1 & Case2 \\
\hline Brand & Common & Poor \\
\hline Product differentiation & High & High \\
\hline Functional design & Good & Poor \\
\hline Knowledge generation & Common & Common \\
\hline Output value & 84.8 & 76.9 \\
\hline
\end{tabular}

\section{CONCLUSION}

Taiwan had enjoyed two-digit GDP growth rates for several years in the past. However, due to the increasingly intense global economic competition and the exodus of its manufacturing and electronic industries, Taiwan has been suffering severe economic slowdown and social problems caused by wage growth slower than inflation for nearly 20 years. To solve this economic development predicament, Taiwan has put in place several subsidy policies to promote the development of cultural and creative industries as the next source of economic growth momentum after the electronic industry.

With the assistance from the Delphi experts in this study, it is confirmed that the four influence factors for the development of cultural and creative industries are brand, product differentiation, functional design and knowledge generation. In addition, through the Delphi fuzzy model established in this study, 81 combinations of inputs of the four factors can be easily converted into quantitative information, providing helpful references for policy makers and regulators to understand the fundamental problems in promoting the development of industries with local characteristics and consequently enhance the effectiveness of their policies.

\section{References}

[1] M. Trimarchi, "The economics and policy of creativity: the Italian perspective,” Creative Ind. J., vol. 2, pp. 231-246, 2009.

[2] Cultural and creative industries promotion service network, Ministry of Culture, launched on October 1st, 2009. (visited on March 28th, 2014) http://cci.culture.tw/cci/cci/law_detail.php?sn=3838.

[3] T.R. Wojan and D. Mc Granahan, “Ambient returns: creative capital's contribution to local manufacturing competitiveness," Agr. Resource Econ. Rev., vol. 36, pp. 133-148, 2007.

[4] Taiwan Ministry of Economic Affairs, 2005 White Paper on SMEs, Small and Medium Enterprise Administration, Taipei, Taiwan, 2015. ISBN 9860020264.

[5] J.H. Hsia, Introduction to Cultural and Creative Industries, Taipei: WuNan Publishing, 2008. ISBN 978-957-11-5223-3.

[6] A. Pratt, "Cultural industries and public policy: an oxymoron," Int. J. Cult. Pol., vol. 11, pp. 31-44, 2005.

[7] D. Throsby, "Cultural capital,” J. Cult. Econ., vol. 23, pp. 3-12, 1999.

[8] A. Pratt, "The cultural economy: a call for specialized "production of culture' perspectives,' Int. J. Cult. Stud., vol. 7, pp. 117-128, 2004. 
[9] R. Towse, "Why has cultural economics ignored copyright?" J. Cult. Econ., vol. 32, pp. 243-259, 2008.

[10] M. Riley, F. MacMillan, and K. Bowery, "New directions in copyright law, volume 3", J. Cult. Econ., vol. 31, pp. 337-341, 2007.

[11] A. Scott, "Cultural-product industries and urban economic development: prospects for growth and market contestation in global context," Urban Aff. Rev., vol. 39, pp. 461-490, 2004.

[12] S.E. Siwek, "Copyright industries in the U.S. economy-the 2012 report," International Intellectual Property Alliance, http://www.iipa.com/pdf/2013_Copyright_Industries_Full_Report.

[13] D. Hesmondhalgh, "Bourdieu, the media and cultural production," Media, Cult. Soc., vol. 28, pp. 211-232, 2006.

[14] B. Casey, R. Dunlop, and S. Selwood, "Culture as commodity? the economics of the arts and built heritage in the U.K.," J. Cult. Econ., vol. 21, pp. 355-360, 1997.

[15] L. Petrova and D. Throsby "The economics of cultural policy," J. of Cult. Econ., vol. 35, pp. 237-240, 2011.

[16] J.L. Sintas and E.G. Álvarez, "The consumption of cultural products: an analysis of the Spanish social space," J. Cult. Econ. Vol. 26, pp. 115138, 2002.

[17] A. Collins, "Innovativeness, creativity and public policy: anecdotes, conventional wisdoms and evidence," Creative Ind. J., vol. 2, pp. 247257, 2009.

[18] T. Cowen, "Why everything has changed: the recent revolution in cultural economics," J. Cult. Econ., vol. 32, pp. 261-273, 2008.

[19] D. Mato, "All industries are cultural," Cult. Stud., vol. 23, pp. 70-87, 2009.

[20] O. Velthuis, M. Hutter, and D. Throsby, "Beyond price. Value in culture, economics and the arts," J. Cult. Econ., vol. 32, pp. 321-324, 2008.

[21] D.A. Aaker, "The Value of Brand Equity," J. Bus. Strat., vol. 13, pp. 27-32, 1992.

[22] H. Clark, "Back to the future, or forward? Hong Kong design, image, and branding," Des. Issues, vol. 25, pp. 11-29, 2009.

[23] D. Chhabra, R. Healy, and E. Sills, "Staged authenticity and heritage tourism," Ann. Tourism Res., vol. 30, pp. 702-719, 2003.
[24] W.C. Chang and T.Y. Wu, "Exploring types and characteristics of product forms," Int. J. Des., vol. 1, pp. 3-14, 2007.

[25] R.E. Caves, "Contracts between art and commerce," J. Econ. Perspect., vol. 17, pp. 73-83, 2003.

[26] R. Chitturi, R. Raghunathan, and V. Mahajan, "Delight by design: the role of hedonic versus utilitarian benefits," J. Market., vol. 72, pp. 48-63, 2008.

[27] E.M. Okada, "Justification effects on consumer choice of hedonic and utilitarian goods," J. Market. Res., vol. 42, pp. 43-53, 2005.

[28] M. Osterloh and B.S. Frey, "Motivation, knowledge transfer, and organizational forms," Organ. Sci., vol. 11 , pp. 538-550, 2000.

[29] E. Ziglio and M. Adler, "Gazing into the Oracle: the Delphi Method and Its Application to Social Policy and Public Health," London: Jessica kingsley, pp. 1-33, 1996.

[30] J.W. Murry Jr and J.O. Hammons, "Delphi: a versatile methodology for conducting qualitative research," Rev. High Educ., vol. 18, pp. 423$436,1995$.

[31] S.L. Hsueh and M.R. Yan "A multi-methodology contractor assessment model for facilitating green innovation-the view of energy and environmental protection," Sci. World J., vol. 2013, Article ID 624340 , 2013.

[32] S.L. Hsueh, J.R. Lee, and Y.L. Chen, "DFAHP multicriteria risk assessment model for redeveloping derelict public buildings," Int. J. Strat. Property. Manag., vol. 17, pp. 333-346, 2014.

[33] D.F. Li and J.B. Yang, "Fuzzy linear programming technique for multiattribute group decision making in fuzzy environments," Inform. Sciences, vol. 158, pp. 263-275, 2004.

[34] S.L. Hsueh, "A fuzzy logic enhanced environmental protection education model for policies decision support in green community development," Sci. World J., vol. 2013, Article ID 250374, 2013.

[35] S.L. Hsueh, "A fuzzy utility-based multi-criteria model for evaluating households' energy conservation performance: a Taiwanese case study," Energies, vol. 5, pp. 2818-2834, 2013. 